\title{
EL REDESCUBRIMIENTO \\ DE LA COMUNIDAD
}

RESUMEN. El concepto de comunidad tiene un valor polisémico. La sociología ha descubierto relaciones comunitarias en casi todas las instituciones sociales, confundiendo, con frecuencia la necesidad del encuentro social con la persistencia de la comunidad. En condiciones modernas ni la escisión-público-privado ni la esfera privada, ni los enclaves de vida, ni por supuesto, la sociedad íntima o el narcisimo colectivo parecen motivo suficiente para refundar valores comunitarios. Sólo el mantenimiento de un tipo u otro de tradición es elemento significativo para crear comunidad. Aquellos grupos (étnicos, religiosos o de género) que aseguran su marco de referencia desde la memoria histórica son los poseedores del discurso comunitario.

\section{INTRODUCCION}

La comunidad es uno de los conceptos más controvertidos de los empleados por la Sociología. Es un valor polisémico que hace referencia a múltiples realidades y perspectivas, desde aquellos que emplean la comunidad como objetivo de la anhelada vida buena, hasta aquellos otros con fines nás prosaicos que hablan de conunidad de interés o los que están empeñados en su particular cruzada intentando construir comunidad siguiendo los dictados de la tradición. Unos discursos y otros están convencidos de que la comunidad obedece al imperativo antropológico del en- 
cuentro social y a la profunda necesidad de crear sentido y dar forma a la socialidad humana.

Suele ocurrir que conceptos como comunidad pueden agotarse por carecer de capacidad explicativa, en cuanto las características adjudicadas a tal evidencia social no son fáciles de encontrar en nuestras complejas sociedades. El discurso sobre la comunidad está presuponiendo: identificación del individuo con el grupo, interacción mantenida a lo largo del tiempo, conocimiento mutuo, solidaridad grupal, individuos entregados al grupo y conciencia de pertenencia como conciencia del Nosotros.

La perspectiva sociológica sobre la comunidad ha «bebido» del mito comunitario. Mito generado, por una parte, por el pensamiento conservador y, por otra, por el planteamiento de Tönnies. Si la tipología de Tönnies describía el tránsito de la Gemeinschaft a la Gessellschaft; los conservadores construían una explicación de la sociedad postrevolucionaria, en términos tradicionales. La razón moderna y el contrato social se les presentaban como el final de un trayecto, el fin de «su» pauta cultural de vida grupal. Por eso su discurso comunitario es perpetuación de la tradición; la tradición explica la comunidad, o mejor aún, la tradición es la comunidad. Pero la vida en la sociedad tradicional no tiene, en absoluto, carácter bucólico, sino que, por el contrario, el miedo, la dependencia y el control estricto, amén de la falta de libertades, son sus características significativas. La tradición creaba un orden de seguridad e integraba a los individuos en un mundo injusto, pero coherente. La sociedad moderna debe enfrentarse a la producción de nuevos principios de articulación social. No podían proceder de la «extinta» sociedad tradicional, ni de sus formas de socialidad más notables. La Sociología debe, primero, comprender el cambio, las mutaciones que la revolución política y la revolución industrial están institucionalizando. Por otra parte, debe encontrar una explicación coherente al cambio y, por supuesto, descubrir nuevos principios que articulen la complejidad y fragmentación de un mundo, que ha encontrado en el individuo y en un nuevo concepto de sociedad comunitaria sus principios y sus límites. La ambigüedad, cuando no la paradoja, se instala como principio organizador de la vida social.

La comunidad encuentra una nueva definición en la idea de nación. La nación permite transformar la compleja sociedad moderna en comunidad. Claro está que ésta alberga en su seno múltiples realidades y micromundos, con lo que no puede asegurar la coherencia tradicional. Los comportamientos comunitarios quedan definidos como refugios privados. Sólo adquieren significatividad en el encuentro intersubjetivo, que raras veces cumple las condiciones para refundar la comunidad.

Los discursos que desde la Sociología estudian la comunidad se refieren a la relación entre el individuo y su medio ambiente desde el punto de vista de las relaciones entre los individuos humanos, por un lado, y las instituciones y formas de estructuración social, por el otro. Pero la comu- 
nidad analizada no es sino una parte del paisaje urbano y de los tipos humanos que lo pueblan. La comunidad no es más que un grupo actuando en condiciones definidas por su medio ambiente y las instituciones que lo regulan.

Tampoco la sociedad íntima, la esfera privada y, mucho menos, los enclaves de vida, son elementos significativos de comunidad, en tanto no están fundados desde el grupo, sino desde el sí mismo del individualismo y del éxito personal. No obstante, el anhelo comunitario sigue siendo motivo permanente de actividad teórica y práctica.

La hipótesis que me gustaría defender a lo largo del artículo es que el redescubrimiento de la comunidad sólo puede hacerse en el interior de un micromundo atravesado por la permanencia de una tradición. Por eso los grupos étnicos, religiosos o de género aparecen hoy como los herederos de referencias comunitarias. Enclaves de vida, esfera privada o sociedad íntima son sustitutos funcionales de una imposible comunidad.

En el fondo no es más que un capítulo más de la incesante búsqueda del sentido, pero las condiciones de reproducción de la complejidad reducen el espacio y las condiciones comunitarias a realidades «marginales», donde junto al espíritu moderno anida, mantenida o inventada, una tradición.

\section{LA PERSPECTIVA COMUNITARIA}

Algunos sociólogos parecen empeñados en perseguir, con afán, la vida buena. No porque hayan descubierto un mundo mejor, bastante tienen con el presente, sino porque se han obligado a interpretar la vieja raíz comunitaria que anida en el encuentro social. El redescubrimiento de la socialidad está relacionado con el basamento utópico del quehacer sociológico y, especialmente, con la sentida necesidad de «rescatar» la problemática de las relaciones intersubjetivas y las formas primarias de socialidad ${ }^{1}$.

${ }^{1}$ Es conocido que, en su largo peregrinar, la tradición sociológica ha recorrido largos y, en ocasiones, tortuosos caminos. El declive de los grandes paradigmas -EstructuralFuncional y Marxismo- ha permitido la resurrección de perspectivas «marginales». Una de las direcciones del descubrimiento ha seguido el regreso a la subjetividad. La preocupación microsociológica, al interesarse en la interacción, en la vida cotidiana y en mecanismo de constitución de lo social, sitúa al encuentro social y a las estrategias que lo producen en el centro de su perspectiva. La teoría del intercambio, el interaccionismo, la etnometodología o la fenomenología social son otras tantas formalizaciones teóricas que persiguen este objetivo. Es muy sugerente el análisis del neofuncionalista J. AlEXANDER, Las teorias sociológicas desde la segunda guerra mundial, Gedisa, Barcelona, 1990; Karen Knov Celtina/A. Cicourel (comps.), Advances in Social Theory and Methodology. Towards an Integration Micro and Macro Sociology, Londres, 1981; R. Collins, «On the Microfoundations of Macrosociology», American Journal of Sociology, 1981; R. Collins, Three Sociological Traditions, New York, Oxford University Press, 1985. Entre nosotros, A. Giddens/J. Tunner (comps.), La teoría social, boy, Alianza, Madrid, 1990. También, Nigel G. Fielding, Actions and Structure, Sage Publications, 1988. Es muy sugerente la obra colectiva: J. AlexANDER, B. Giesen, R. Munch y N. Smelser, The Micro-Macro Link, University of California Press, Berkeley, 
Al margen de su actualidad es perfectamente legítimo coincidir con R. Nisbet ${ }^{2}$ cuando dice que «de las ideas-elementos de la sociología, la más fundamental y de más largo alcance es la de comunidad».

Rastrear los elementos comunitarios en comportamientos colectivos o en teorías sociales, sería una labor ardua y prolija ${ }^{3}$, y no tanto por su inaprensibilidad, sino por ser un término polisémico, empleado con profusión y, en ocasiones, con ligereza. En muchos autores está presente una mitificación de la comunidad, como si las formas de socialidad comunitarias fueran el único basamento del comportamiento social y sin reconocer

1987; S. N. Eisenstadt y H. J. Helle (eds.), Perspectives on Sociological Theory, Sage Publications, 1987. Algunos de los problemas que plantea tal síntesis se encuentran recogidos en A. Giddens, The Constitution of Society, Polity Press, Cambridge, 1984; del mismo autor, Social Theory and Modern Sociology, Stanford University Press, 1987. J. E. RodrfGuez IbAÑEz, La perspectiva sociológica, Taurus, 1990 , demuestra una sutil sensibilidad para esta problemática.

2 R. Nisber, La formación del pensamiento sociológico, Ed. Amorrortu, B. Aires, 1964, p. 40 .

${ }^{3}$ Los sociólogos, antropólogos, historiadores, politólogos, filósofos morales y sociales e incluso economistas con «pretensiones humanistas» emplean sin recato el término comunidad. La diversidad de autores y perspectivas sería muy larga. Entre los más sugerentes, aparte de los clásicos, citaría a Ch. H. Cooley, Social Process, Southern Illinois University Press, 1966. Por supuesto, la Escuela de Chicago: The City Suggestions for Investigation of Human Bebavior in the Urban Environment, The University of Chicago Press, Chicago, 1925. También, G. A. Theodorson (comp.), Estudios de ecologia bumana, Ed. Labor, 1974, 2 vols. Entre los sociólogos, también, S. Lynd y H. M. Lynd, Middletown: A Study of Contemporary American Cultur, Harcourt Place, N. York, 1929. La comunidad es especialmente recurrente en los análisis de las relaciones étnicas. Véanse B. Misra y J. Preston (eds.), Community, Self, and Identity, Mouton, Chicago, 1978; J. FARLEY, Mayority-Minority Relations, Prentice Hall, New Jersey, 1988; N. Gazer y D. P. Moynihan, Etbnicity, Theory and Experience, Harvard University Press, Cambridge, 1975; Colin H. Williams y C. Kofman (eds.), Community Conflict, Partition and Nationalism, 1989; C. Fried (ed.), Minorities; Community and Identity, Spring-Verlag, N. York, 1983; W. Kornblum, Blue Collar Community, University of Chicago Press, 1974; A. P. CoHEN, The Symbolic Construction of Community, Ellis Horwood Limited, 1985; C. Bell \& Unwin, Londres, 1971; F. BARTh, Los grupos étnicos y sus fronteras, Fondo de Cultura Económica, México, 1978; R. REDFIELD, The Little Community, Almquist \& Wiksells Boktoryiker, Stockholm, 1955; A. D. SMITH, The Ethnic Revival in the Modern World, Cambridge University Press, 1981; M. STIN, The Eclipse of Community and Social Change, Rutges University Press, 1978; R. Lingeman, Small Town, American Putnam, N. York, 1984. Es magnífico el estudio de R. BellaH, W. M. Sullivan, A. Swidlep y S. M. Tipton, Hábitos del corazón, Alianza, Madrid, 1989; R. SennetT, Declive del bombre público, Península, Barcelona, 1984. La historia ha enriquecido los estudios de comunidad con nuevas perspectivas; los nombres de E. J. Hobsbawm, E. P. Thompson, C. Ginzburz, T. Skocpol, P. Burke, R. Chartier, E. Leroy Ladurie, J. Le Goff, P. Aries, G. Duby, J. Braudel, Ch. Tilly, J. Delameau, etc., no pueden ser olvidados por ningún sociólogo que se dedique a comprender procesos y mecanismos sociales para la construcción del encuentro social comunitario. La filosofía moral y política no se ha quedado atrás en el enésimo descubrimiento de la comunidad. Véase G. BELLO, V. HeRnÁNDEZ, A. Sierra, C. Mesa, J. A. Acinar y P. Rodenos, Comunidad y utopia, Ed. Lenna, 1990. También, Fred R. Dallmayr (ed.), From Contract to Community Political Theory at the Crossroads, N. York, 1978; J. Rawls, Teoría de la justicia, Fondo de Cultura Económica, México, 1979; Fred Dallmayr, Twilight of Subjectivity. Contributions to a Pos Individualist Theory of Politics; J. Habermas, Teoria de la acción comunicativa, 2 vols., Taurus, Madrid, 1988. 
que el fundamento de su fundación es el imperativo antropológico del encuentro y de la relación social. Como expresa A. W. Greeley, «se diría que lo ocurrido (...) ha sido que la sociedad se ha vuelto enormemente compleja, con grandes pirámides de estructuras asociativas que se han ido erigiendo sobre un sustrato de relaciones primarias (...). Las comunidades formadas en torno a sus vínculos primarios habrán de considerarse no simplemente como una riqueza y una valiosa diversidad culturales, sino como pilares básicos de la estructura social urbana» ${ }^{4}$.

No todos los comportamientos sociales pueden ser definidos como comunitarios $^{5}$. La comunidad reúne características propias; en primer lugar es relevante la existencia de un grupo social cohesionado, donde los individuos puedan proyectarse como personalidades globales, al margen de roles o status. Por otra parte, es necesaria la duración en el tiempo de tal tipo de relaciones porque no puede haber comunidad si no hay conocimiento mutuo, y éste sólo se alcanza prolongando en el tiempo la interacción. Parece también que el individuo debe ser reconocido como integrante de un grupo, no tanto en su individualidad, sino como miembro de una colectividad peculiar. Es la colectividad quien da nombre al individuo. De esta forma la desviación del sujeto, con respecto al grupo, está penalizada, y los comportamientos individuales controlados por la solidaridad grupal. Se espera del individuo que esté totalmente entregado al grupo y que su vida sea la del grupo. Las formas de socialidad reconocen grupos y sujetosmiembros del grupo, pero nunca individuos en sí mismos. El individualismo sería una forma patológica de vivir en comunidad.

La socialidad comunitaria crea fuertes sentimientos de pertenencia. El grupo se les presenta nítidamente, cohesionado con la conciencia del Nosotros $^{6}$. Los contornos del grupo comunitarizado están estrechamente definidos. Nadie que no sea nombrado miembro del grupo puede relatar la historia grupal.

El grupo necesita al otro ${ }^{7}$, porque, por una parte, requiere el reconocimiento exterior para poder reproducir la idea de Nosotros y mantener así

${ }^{4}$ A. M. Greeley, El bombre no secular. Persistencia de la religión, Ed. Cristiandad, Madrid, 1974, pp. 46-47.

s Es muy sugerente leer a R. Nisbet, El vínculo social, Vicens Vives, Barcelona, 1975, especialmente el capítulo dedicado al grupo, porque, de forma pedagógica y brillante, hace una magnífica introducción a la definición de la comunidad. Por otra parte, su obra The Quest for Community, Oxford University Press, 1953, sigue siendo un magnífico estudio de los «vaivenes» históricos de la comunidad, su «ocaso» y su descubrimiento.

6 Para la significación social de la conciencia del Nosotros sigo los caminos abiertos por A. Schutz, especialmente: Las estructuras del mundo de la vida, Amorrortu, B. Aires, 1977; Estudios de teoría social, Amorrortu, B. Aires, 1974; El problema de la realidad social, Amorrortu, B. Aires, 1975. Son muy sugerentes los análisis de H. TAjFEl, Grupos bumanos $y$ categorías sociales, Herder, Barcelona, 1974. Ni que decir tiene que el libro de F. Barth (ed.), Los grupos étnicos y sus fronteras, Fondo de Cultura Económica, México, 1978, es imprescindible para nuestro planteamiento.

7 Cabría aquí mencionar las contribuciones, ya clásicas pero actuales, de autores como W. G. Summer, W. I. Thomas, F. Znaniecki, R. E. Park, E. S. Bogardus, sin olvidar los 
la cohesión. Quieren que aquello que el grupo dice que es relevante sea reconocido y afirmado por los otros. Si dicen que actúan como $\mathrm{A}$, en contraste con $B$, esperan ser tratados como tales y que su conducta sea interpretada como A y no como B. Por otra parte, reconociendo al Otro puede identificarlo, en unos casos como el desconocido, el extranjero; en otros como el contrincante o el enemigo. Este aspecto es muy importante para la definición comunitaria, ya que permite trazar una frontera simbólica cuyos límites sólo la comunidad controla, aunque el Otro debe distinguirlos. Esto les garantiza la persistencia de una estructura de comunicación donde negociar cotidianamente su diferencialidad.

No es extraño que mantener la frontera se transforme en requisito de supervivencia comunitaria y que las formas de socialidad proyecten rituales de diferencia, bien creando un lenguaje exclusivo para el grupo, bien una estética peculiar (formas de vestir y usar el cuerpo, comportamientos tribales, etcétera).

La vida dentro de la comunidad implica la ausencia de intereses propios y el hecho social de vivir en el grupo y para el grupo. Estar juntos es necesario para sus miembros, porque la compañía es el ritual que garantiza la existencia del Nosotros.

Formas comunitarias se encuentran en medios sociales muy diversos como el estado, la iglesia, la escuela, sindicatos, etc.

La comunidad resume y sintetiza sentimientos y razones, tradición y modernidad. De hecho, no hay institución primaria o secundaria, grande o pequeña, donde no podamos encontrar formas de socialidad comunitarias. Otra cosa distinta es pretender que las estructuras comunitarias rijan los destinos modernos.

Probablemente la tipología de Tönnies ${ }^{8}$ (Gemeinschaft-Gessellschaft), junto al planteamiento conservador, es la que más incidencia tiene en la creación del mito comunitario. Este mito recoge, casi con precisión, las características denotadas por nuestro autor; la comunidad es expresión de la voluntad; es una forma de socialidad natural; la familia es la manifestación más significativa de ella. Las relaciones más importantes se basan en la afectividad y la emotividad, en el respeto y la autoridad. Los valores do-

planteamientos de G. Simmel. Es muy sugerente, aunque un tanto «pasado», el libro de Mary Wood, The Huanger: A Study in Social Relationship, N. York, 1934. Sigue siendo imprescindible el ensayo de A. SCHUTZ, «El Forastero», recogido en Estudios sobre teoría social, Amorrortu, B. Aires, 1974, pp. 95-108; la obra de A. P. CoHEN, The Symbolic Construction of Community, op. cit.; también, M. Glazer y D. P. MoYnihan, Etbnicity, Theory and Experience, op. cit.; el libro de H. TAJPEL, Grupos bumanos y categorías sociales, op. cit., o el discípulo y colaborador de H. Tajfel, V. TURNER, Redescubrir el grupo social, Morata, Madrid, 1987; la obra de I. BARTH, Grupos étnicos y sus fronteras, op. cit. Es sugerente y esclarecedor Clifford GEerTz en La interpretación de las culturas, Gedisa, Barcelona, 1987. Véase Ander GURRUTXAGA, El código nacionalista vasco durante el franquismo, Anthropos, Barcelona, 1985, especialmente pp. 34-53.

${ }^{8}$ F. Tönnies, Comunidad y asociación, Península, Barcelona, 1979. 
minantes en la vida comunitaria se fundan en la unidad y en la totalidad; la solidaridad, el desinterés y la sinceridad.

El tránsito de la comunidad a la asociación, que el propio Tönnies describiera, dejaba abierto el interrogante, origen del redescubrimiento comunitario; ${ }^{9}$ si las sociedades tradicionales se mantienen unidas mediante ideas y sentimientos comunes, ¿qué mantiene unida a la sociedad moderna? El descubrimiento decimonónico de la comunidad es, en el fondo, el discurso sobre la pérdida, sobre la separación. Reacción frente a un mundo que cambia y, especialmente, frente a los costes del cambio. La mirada se dirige al presente, pero el pasado, la tradición, está presente en la ambigüedad de los nuevos tiempos, porque la mitificación de la comunidad «bebe» directamente de la organización comunitaria tradicional y de las ambigüedades y paradojas de la instauración moderna.

En condiciones modernas, los planteamientos sobre la comunidad son analizados desde tres grandes perspectivas: en primer lugar, como el pensamiento conservador, desde la progresiva desaparición de la tradición y de las formas de socialidad tradicionales; por otra parte, desde la afirmación del individualismo y las relaciones asociativas y, por último, desde la paradoja y ambigüedad de la razón moderna, a medias entre la autonomía y la dependencia y con un concepto de sociedad que intenta absorber las tensiones internas que generan las contradicciones del orden nuevo. Unos $y$ otros «buscan» en la comunidad de memoria ${ }^{10}$. En unos casos para justificar su discurso comunitario ${ }^{11}$, en otros para tomarlo como referencia y entender el presente desde el pasado ${ }^{12}$.

9 Es imprescindible el capítulo que R. NISBET dedica al análisis de la comunidad en $L a$ formación del pensamiento sociológico, op. cit. Para seguir el proceso, la ya mencionada obra del mismo autor The Quest for Community, op. cit.

${ }^{10}$ La comunidad de memoria es un término acuñado por R. BELLAH, R. MADSEN, W. M. Sullivan, A. Swidler y S. M. Tipton en su obra Hábitos del corazón, Alianza, 1989, pp. 203. 206.

11 Esta postura es mantenida por el pensamiento conservador, que manifestaba tres claras preocupaciones. Por una parte, significaba la problematización de la realidad tradicional, que había tenido en la Religión, la Monarquía y los grupos locales sus factores de integración y legitimación. Por otra parte, manifestaban la significación social de la realidad tradicional. Con todos sus defectos, la tradición había mostrado un alto grado de eficacia. La red de evidencias sociales en las que se había fundado habían mantenido cohesionada, por siglos, la sociedad. En tercer lugar, plantean dos problemas clave: el origen de las nuevas formas de socialidad y la necesidad de crear un orden de seguridad que dote de marcos de referencias a los individuos. Hay un magnífico análisis de estas posturas en R. NISBET, "Conservadurismo», en Historia del pensamiento sociológico, Amorrortu, B. Aires, 1984, pp. 166 y ss. Es imprescindible L. DE BONALD, Oeuvres, Librairie D’Adrien Le Clere, París, 1840; J. De Marstre, Oeuvres Complets, 1884-86. Véanse también las páginas que al conservadurismo dedica I. ZEITLIN, Ideologia y teoria sociológica, Amorrortu, B. Aires, 1970, pp. 47-67.

12 La sociología clásica no olvida, a mi entender, la profunda significación de las relaciones comunitarias. La Gessellschaft de Tönnies anuncia más el triunfo de la razón moderna que la desaparición de la Gemeinschaft. En Durkheim, la producción de realidad moral integradora es consustancial a la solidaridad orgánica. Para Max Weber, la acción racional con arreglo a fines no elimina ni la acción racional valorativa, ni la afectiva, ni la tradicional. 
Una hipótesis que me gustaría plantear es que la definición moderna de comunidad sigue anclada en la tradición. Es, en el fondo, la búsqueda mitificada de la comunidad de memoria y de formas de socialidad que permitan responder a la vieja pregunta durkheimiana: ¿qué mantiene unida la sociedad? ${ }^{13}$.

Si la pluralización de los mundos de vida ${ }^{14}$ y la privacidad de la vida ${ }^{15}$ conducen a la creación de nuevas formas de socialidad comunitaria, a la especialización privada del mundo comunitario y a la confusión comunidad=enclaves de vida ${ }^{16}$. También parece cierto que frente al peligro de la comunidad destructiva ${ }^{17}$ o de la subinstitucionalización de la esfera privada $^{18}$ se puede erigir la ambigüedad como principio porque sólo en virtud de la ambigüedad es posible concebir que pueda crearse una comunidad de intereses morales a partir de una comunidad donde «a nadie pueda importarle» ${ }^{19}$.

\section{LA COMUNIDAD DE LA TRADICION}

R. Williams ${ }^{20}$ indica que individuo significa inseparable en el pensamiento medieval. Presentar a un individuo era dar noticias del grupo del cual era miembro. $\mathrm{Ni}$ que decir tiene que el individuo autónomo no existe en la referencia tradicional. Su nombre procede del grupo. El sujeto es inseparable del grupo al cual pertenece y de la localidad de nacimiento.

Una breve descripción de la sociedad tradicional nos indica ${ }^{21}$ que es una comunidad cerrada y estática; las nuevas ideas están contenidas por los

${ }^{13}$ Ni que decir tiene que semejante pregunta es respondida en De la división del trabajo social, Schapire, 1973; Las formas elementales de la vida religiosa, Akal, Madrid, 1982; El suicidio, Akal, Madrid, 1983. La obra de S. Lukes, Emile Durkheim: su vida y su obra, Centro de Investigaciones Sociológicas, Madrid, 1988, es un magnífico estudio articulado desde semejante pregunta. Entre nosotros, es esclarecedor el texto de Luis Rodríguez ZúÑiga, Para una lectura crítica de Durkbeim, Akal, Madrid, 1978.

${ }_{14}$ Es un concepto con clara raíz en la obra de A. Schutz, pero desarrollado, desde una particular teoría de la modernidad, por P. BERGER, B. BERGER y H. KELLNER, Un mundo sin hogar, Santander, 1979, pp. 63 y ss.

${ }_{15}$ Hay que tener presente el desarrollo que hace el libro colectivo, coordinado por P. Aries y G. Duby, Historia de la vida privada, Taurus, Madrid, 1989, especialmente los tomos 3. y 4.'. Un estudio muy valioso es el de Helena BEJAR, El ámbito intimo. Privacidad, individualismo y modernidad, Alianza, Madrid, 1988, donde, además, encontraremos múltiples referencias a esta problemática.

16 Tomo este término del citado texto de R. BELlaH, op. cit., pp. 103-108.

17 Véanse R. SennetT, Declive del hombre público, Ed. Península, Barcelona, 1976; Vida urbana e identidad personal, Península, Barcelona, 1974; Narcisismo y cultura moderna, Kairós, Barcelona, 1978.

18 P. Berger, B. Berger y H. Kellner, op. cit., p. 177.

19 A. DaWe, «Teorías de la acción social», en R. NisBeT y T. BOTTOMORE, op. cit., p. 472.

20 R. Williams, The Long Revolution, Chatto \& Windus, Londres, 1961, p. 73.

${ }^{21}$ Las obras sobre la sociedad tradicional y sobre la sociedad histórica medieval son muy abundantes. Voy a citar aquí aquellas que me han sido de gran utilidad para este 
poderes dominantes (iglesia y señor). No les afectan movimientos de ningún tipo, ni están sujetas a movilidad geográfica o social. El tiempo está controlado y la rutina impone su inexorable presencia. Al tratarse de colectividades pequeñas el control que unos y otros ejercen sobre la vida social es extremo. La existencia se vive de forma abierta. No podemos hablar de dimensiones, pública o privada, ya que la invención burguesa de las esferas pública y privada no está entre las posibilidades humanas.

El individuo tradicional, tal y como nos es descrito, vivía en un mundo donde las relaciones están preestablecidas. Esta realidad es aceptada sin cuestionamientos; es evidencia social. La persona aceptaba su lugar dentro de él y tenía conciencia de sí mismo en cuanto miembro de su grupo.

En este medio la comunidad es la forma dominante de estructuración social. No es que la comunidad tenga presencia activa en la tradición, sino que es la tradición misma.

Este entramado social era justificado en términos religiosos. Ahora bien, si la presencia de la iglesia y la religión era innegable, su poder no es tan absorbente, al menos en todos los estamentos, como se pretende. Parece demostrado ${ }^{22}$ que las masas campesinas no asistían regularmente a la iglesia e ignoraban los mensajes fundamentales de los eclesiásticos. Sólo las reformas del siglo XVI introducirán, a través de mecanismos excepcionales (Inquisición y reforma del clero), orden a la desorganizada vida eclesiástica. La barrera de la lengua (vernáculas frente al latín), altos niveles de analfabetismo y el desconocimiento de la escritura dificultan muy mucho la normal penetración del discurso religioso-eclesiástico. La tesis más verosí-

trabajo. El texto de A. DE TOCQueville, El Antiguo Régimen y la Revolución, Guadarrama, Madrid, sigue siendo insustituible. Durkheim, Tönnies y Max Weber siguen siendo aproximaciones muy valiosas. El libro de T. PARSONS, El sistema de las sociedades modernas, Trillas, México, es una valiosa aportación. El conocimiento inmediato lo presenta la historia social. La obra clave es la de M. BLOCH, La sociedad feudal, Akal, Madrid, 1982; J. LE GofF y otros, El hombre medieval, Alianza, Madrid, 1988. Es imprescindible J. Delumeau, El miedo en Occidente, Taurus, Madrid, 1989; J. LE GofF, Tiempo, trabajo y cultura en el Occidente medieval, Taurus, Madrid, 1983; R. Boutruche, Señorio y feudalismo, 2 tomos, Siglo XXI, Madrid, 1989; J. Le Goff (comp.), Herejías, sociedades, Siglo XXI, Madrid, 1987; P. Aries y G. Duby, Historia de la vida privada, tomos 2. ${ }^{\circ}$ y.$^{\circ}$, , Taurus, Madrid, 1988 y 1989; E. Le Roy Ladurie, Montillon, aldea occitana, Taurus, Madrid, 1981 (es una magnífica monografía, a «caballo» entre la historia, la etnografía y la sociología, sobre la vida en dicha aldea); E. Le Roy Ladurie, Les Paysans de Languedoc, Flammarion, París, 1969; P. BuRKe, La cultura popular en la Europa moderna, Alianza, Madrid, 1991; M. BAJTIN, La cultura popular en la Edad Media y el Renacimiento, Alianza, Madrid, 1988; N. ELIAs, El proceso de civilización, Fondo de Cultura Económica, México, 1987.

${ }^{22}$ La tesis de la religiosidad medieval ha sido cuestionada por un amplio abanico de autores. Véanse P. BuRke, Cultura popular en la Edad Moderna, op. cit.; J. Delumeau, Histoire de la Bretagne, Tolouse, 1969; J. Delumeau, El miedo en Occidente, op. cit.; R. M. Goodridge, «The Ages of Faith-Romance or Reality», The Sociological Review, vol. 23, núm. 2, 1975, pp. 381-946; E. LE Bras, Déchristianisation-mot fallacieux. Social Compass, op. cit.; E. Le Roy Ladurie, Montaillan, op. cit.; D. Martin, A General Tbeory of Secularizations, Oxford, 1978; G. Owst, Literatur and Pulpit in Medieval England, Oxford, 1967; K. Thomas, Religion and the Decline of Magic, Londres, 1971; B. WILSON, La religión en la sociedad secular, Labor, Barcelona, 1969. 
mil ${ }^{23}$ afirmará que la élite urbana fue un grupo social católico ortodoxo y practicante, pero la mayoría rural conservó sus creencias y, en algunos casos, prácticas precristianas.

Los movimientos milenaristas ${ }^{24}$ son un indicador preciso del funcionamiento social de la religiosidad popular y de los lugares sociales que ésta ocupaba.

La estructura social de la tradición supone lo que J. Stuart Milli2s y antes que él Tocqueville ${ }^{26}$ habían descrito; los aristócratas y servidores llegan a estar sólidamente identificados unos con otros, pese a la distancia social que los separa. La idea de dependencia es dominante en la organización comunitaria tradicional.

Esta estructura de autoridad implica la apropiación de las funciones de gobierno, de manera que en un mismo territorio rige una autoridad absoluta dentro de las diversas jurisdicciones y una política de lealtades y alianzas entre ellos.

Derechos y obligaciones dependen del status, de la herencia o de la pertenencia a una organización dotada de inmunidades y libertades. Salvo para los poderosos, el status implica una relación legal o política directa con el rey. Esa forma política define, también, la situación de aquellos que no gozan de un feudo o de inmunidades y están excluidos del ejercicio de derechos públicos.

Esta base de poder: territorial, jerárquica y feudal, tenía su proyección económica en la posesión de la tierra. La fuerza de trabajo campesina vivía en una posición legal «no libre», dependiente de un señor que, generalmente, era un individuo $y$, a veces, la iglesia.

La organización política de la tradición dependía de un sistema de lealtades basadas en el rango hereditario, el control de la tierra como principal recurso económico y el ejercicio de la autoridad pública. Todos los que no eran propietarios quedaban excluidos de la participación directa en los asuntos públicos. Los grupos, en situación de dependencia económica, como tales, no tienen derechos; es el caso de arrendatarios, jornaleros, trabajadores regulares y sus servidores. Se los considera pertenecientes a la jurisdicción de su señor y, en consecuencia, representados por éste. La política no estaba asociada a derechos individuales ni tampoco al usufructo del poder, era condición de la lógica dependiente y ésta, a su vez,

${ }^{23}$ Hay un interesante análisis en N. Abercrombie, S. Hill y B. J. Turner, La tesis de la ideologia dominante, Siglo XXI, Madrid, 1987, pp. 67-145; J. DelumeAu, El miedo en Occidente, op. cit., pp. 307-360.

${ }_{24}$ N. CoHn, En pos del Milenio, Alianza, Madrid, 1985; el libro de J. Le Goff (comp.), Herejías y sociedades, Siglo XXI, Madrid, 1987; J. Delumeau, El miedo en Occidente, op. cit.; E. Le Roy Ladurie, Les Paysans de Languedoc, op. cit.; E. Le Roy Ladurie, Montaillon, op. cit.; M. MOLlAT y P. WOLFF, Uñas azules, jacques y ciampi. Las revoluciones populares en Europa en los siglos XIV y XV. Siglo XXi, Madrid, 1976.

${ }_{25}$ J. Stuart Mill, Principios de economía politica, Ed. Fondo de Cultura Económica, México, 1951.

26 A. DE Tocqueville, El Antiguo Régimen y la Revolución, op. cit. 
funcionaba si cada cual estaba en su sitio. La fórmula, magistralmente recogida por $\mathrm{G}$. Duby ${ }^{27}$, de los tres órdenes medievales, delata una comunidad societaria ${ }^{28}$, interrelacionada y definida en su centro ${ }^{29}$ por una intrincada red de relaciones sociales. La dependencia es vínculo de cohesión. De aquí que la subordinación del siervo al señor, sea también obligación del señor hacia el siervo. El patrimonialismo ${ }^{30}$ es la estructura tradicional de un universo cerrado y finito.

Ni la ciudad ni los gremios escapan a la regulación cohesionada de la vida social. Las corporaciones gremiales tradicionales ${ }^{31}$, $\tan$ poderosas en las ciudades-mercados, crearon formas propias de control y desarrollo, impulsaron formas prototípicas de socialidad e incluso impusieron una cultura ciudadana ${ }^{32}$. De hecho, su derrota política no siempre supuso su derrota social, aunque la expansión del Estado y la ruptura de los mercados locales, significaron el «golpe de gracia» para tales formas de organización comunitaria. Sus prácticas económicas y sociales, rígidamente reglamentadas, y su autonomía organizativa ayudaron a crear una cultura específica $^{33}$. En muchas ciudades los espectáculos religiosos eran organizados por los gremios. Todas las cofradías reclutaban a sus miembros entre las distintas corporaciones. Los artesanos tenían también mitos fundacionales y santoral particular. La cohesión de esta estructura comunitaria tradicional no se mantenía sólo por la reglamentación y el control que ejercía la concreta normativa, sino por la producción de un arraigado sentimiento de pertenencia que utilizaba mitos y rituales para su reproducción. Cada oficio tenía su propia cultura, entendida como el conjunto de habilidades y secretos de su trabajo, transmitida de generación en generación. Sus formas de socialidad descansaban en el elemento más significativo que poseían: el secreto del oficio.

La socialidad tradicional tenía otras formas de identificación. Una de las más importantes era la localidad, la tierra donde se había nacido ${ }^{34}$. De

27 G. Duby, Los tres órdenes o lo imaginario del feudalismo, Petres, Barcelona, 1980.

${ }^{28}$ El concepto comunidad societaria está tomado del texto de T. PARsons, El sistema de las sociedades modernas, Trillas, México, 1976.

${ }_{29}$ El problema de la formación de centros es magníficamente analizado por S. N. EISENSTADT, «El Estado, la sociedad y la formación de centros», Revista de Estudios de Opinión Pública, octubre-diciembre 1969, pp. 9-40; E. A. SHILs, «Charisma Order and Status», American Sociological Review, vol. 30, abril 1965, pp. 199-213; E. A. SHILS, «Centre and Periphery», en The Logic of Peronal Knowledge. Essays presented to Michael Polanyi, Londres, 1961, pp. 117-131.

30 Siguen siendo insuperables las páginas que Max WEBER, Economía y sociedad, FCE, México, 1964, dedica a este problema en su análisis de la dominación tradicional (pp. 753 $847)$.

${ }_{31}$ Las páginas que Durkheim dedica a la organización gremial en De la división del trabajo social, op. cit., pp. 7-24, siguen siendo excelentes.

32 Véase P. Burke, La cultura popular en la Europa moderna, op. cit., pp. 77-85.

33 Véase P. Burke, La cultura popular en la Europa moderna, pp. 257-291.

34 A este respecto, vale la pena asomarse a las páginas que J. A. Maravall dedica en su obra Estado moderno y mentalidad social (tomo I), Alianza, Madrid, 1986, pp. 457-500, al concepto de tierra, localidad y patria. 
hecho, el concepto de patria es equivalente al de tierra. La identificación territorial y el grupo al cual se pertenece se interiorizan como referentes de identidad.

La vida social se desplegaba alrededor del hogar y del trabajo. Utensilios, instrumentos, vestidos o penalidades, como las enfermedades, eran tratadas dentro de la casa. La mayoría de las diversiones también se organizaban con criterios autárquicos. Pero la socialidad no sólo se desplegaba en el refugio propio. Otros espacios eran ampliamente utilizados: iglesia, taberna y plazas de mercado ${ }^{35}$. La iglesia podía usarse con propósitos seculares, a pesar de las objeciones del clero. En muchas comunidades era el único espacio accesible para toda la población. La posada o taberna era centro de encuentro social, las actividades preferentes eran la charla, el juego, la diversión, comida y bebida. Pero la cultura cívica encontraba su lugar preferente en la plaza del mercado. Allí acudía la población para comprar o vender productos, de artesanía o de la tierra, intercambiar discursos, escuchar rumores o presenciar variopintas diversiones.

La socialidad que se expresaba en la casa, la iglesia, la taberna y la plaza pública tenía momentos altamente significativos. El más importante era la fiesta: bodas, fiestas patronales, carnavales, etc. La frase que mejor resume esta actitud festiva es la de que el hombre comunitario vivía recordando la fiesta pasada y esperando la siguiente. Como dice R. Callois ${ }^{36}$ : «Este carnaval dura entre navidades y cuaresma; la mitad del año la gente lo pasa recordándolo y la otra esperando el próximo carnaval.»

Las formas de expresar la socialidad dependen, como en todas las sociedades en las que el Estado es débil, de solidaridades colectivas o de dominios que desempeñan una función de protección. P. Aries ${ }^{37}$ define, creo que con amarga precisión, la situación de los individuos: «no se tiene nada - ni siquiera el propio cuerpo- que, llegado el caso, no se halle en peligro y cuya supervivencia no esté supeditada a un vínculo de dependencia».

La comunidad tradicional se funda en el miedo y en la dependencia. Dependencia para asegurar la vida, dependencia del grupo, de la comunidad local, de la familia, del señor o gremio y de la iglesia. La dependencia genera una forma de solidaridad: la vertical. La lealtad al oficio contra otras corporaciones y otras ciudades, socava la solidaridad horizontal, genera una conciencia de grupo frente a cualquier otro grupo. En el campo, la lealtad más significativa era hacia su pueblo, aquí empezaban y terminaban sus obligaciones sociales. Con los forasteros no se podía cooperar y extraños eran todos los que no pertenecían a «su» $\operatorname{comunidad}^{38}$. La

35 Se hace imprescindible asomarse a las páginas de P. BURKE, op. cit., pp. 167-172.

${ }^{36} \mathrm{R}$. Callois, El bombre y lo sagrado, FCE, México, 1984.

${ }_{37}$ P. Aries y G. Duby (comps.), Historia de la vida privada, op. cit., tomo 3, p. 17.

${ }^{38}$ El tratamiento hacia el extraño o el forastero está bien tratado en el libro de $\mathrm{J}$. Delumeau, El miedo en Occidente, op. cit., pp. 53-306. 
definición de grupo psicológico ${ }^{39}$ y esa actitud de desconfianza, hacia todo aquello que era extraño a un pequeño círculo de amigos y familiares, coincidía con la definición del mundo como un hogar de bienes escasos, donde prosperar era casi imposible. Los comportamientos comunitarios debían estar, necesariamente, «ahogados» por su propio modo de vida. No bastaba con querer poner el mundo al revés, sino que los límites sociales eran evidencias que demostraban que la vida conocida era la única posible. Cualquier innovación llevaba a la conciencia de los individuos que componían el orden de la tradición, la inseguridad y el temor. Existían muchas razones que justificaban el miedo ${ }^{40}$ : la guerra, las tasas de mortalidad, el hambre, las plagas, etc. Fuera de la familia, la casa y la aldea, el mundo era totalmente hostil. En estos casos la socialidad se volcaba en espacios de seguridad. Fuera de ellos el mundo era de los extraños y la seguridad un bien escaso. Los proverbios, rituales o la devoción de los santos parecen haber sido creados para protegerse del peligro. El orden tradicional, con sus injusticias y privaciones, engendraba grandes vacíos e insatisfacciones. Las gentes necesitaban definir al otro, al extraño, como enemigo, y como lo necesitaban lo crearon, encontrando en brujas, turcos, judíos, etc., las figuras sobre las que descargar o desplazar sus miedos y la hostilidad generada por las tensiones internas de la comunidad. El Otro se transformó en chivo expiatorio ${ }^{41}$ de la dependencia y el temor. También necesitaban de ocasiones, más o menos regulares, en las que poder expresar filias y fobias. Los rituales festivos, especialmente los carnavales, jugaron siempre este papel.

Estamos todavía en la antecámara de la socialidad moderna, donde no hay vida pública, ni vida privada, pero donde todos pueden tener un papel público, aunque, como dice P. Aries ${ }^{42}$, éste sea el de víctima.

\section{ARTICULACION DE LAS NUEVAS FORMAS DE SOCIALIDAD}

Los cambios que se suceden (Reforma y Contrarreforma, desarrollo de la economía burguesa, gestación del Estado nacional, aparición del individuo, nacimiento de las esferas privada y pública, etc.) suponen un replanteamiento de la comunidad y de las formas de socialidad. Ya no se fundarán sobre el grupo, sino sobre el individuo. Semejante proceso culminará en la Ilustración. La comunidad y sus formas discurren y se manifiestan en la recién creada esfera privada. Esto llevó a que expresiones caracte-

39 Véanse las obras de TAjFel, Grupos bumanos y categorías sociales, Herder, Barcelona, 1984, pp. 193-242, y V. Turner, Redescubrir el grupo social, Morata, Madrid, 1985, pp. 5 . 72.

40 Véase J. Delumeau, El miedo en Occidente, op. cit., pp. 5-35.

${ }^{41}$ Es muy interesante la teoría que construye R. Girard sobre semejante fenómeno. R. Girard, El chivo expiatorio, Anagrama, Barcelona, 1988.

42 P. ArIes, Historia de la vida privada, op. cit., tomo 3, p. 17. 
rísticas de la socialidad popular fueran relegadas y sustituidas por otras manifestaciones que progresivamente utilizaran los medios impresos y la educación como mecanismo de propagación.

La comercialización del ocio y la decadencia de las ferias, fue contrarrestado, en el primer caso, por la progresiva politización de algunas expresiones populares, y en el segundo, por la explosión de la cultura impresa, alfabetizada. Las tabernas no desaparecieron, aunque con la emergencia de los cafés ${ }^{43}$ redujeron algo su actividad. La calle siguió siendo el espectáculo que había sido y el espacio del intercambio por antonomasia; pero a la calle le salió un duro competidor en salones y clubes ${ }^{44}$. En este medio se gesta una opinión pública dispuesta a interrogar las evidencias tradicionales y a opinar sobre todos los asuntos. Ni que decir tiene que la aparición de la prensa $a^{45}$ y el creciente proceso de alfabetización ayudan sobremanera a la gestación de nuevas formas de socialidad. Un dato de esta nueva sensibilidad es la proliferación del libro impreso.

Poco a poco, en un proceso dilatado, desaparecen ciertas manifestaciones de la socialidad tradicional, surgen nuevas formas y nuevas estructuras y, sobre todo, nuevos actores. El clero, la nobleza y la burguesía tenían buenas razones para aceptar y promover el cambio. En el caso del clero, la retirada fue parte de las reformas católica y protestante. Si en 1500 los curas tenían un nivel social y cultural próximo al de sus feligreses, los reformadores demandarán un clero más instruido. En los países protestantes éste solía proceder de las universidades y en los católicos comenzaron a ser educados en seminarios.

Para la burguesía y la nobleza, más importante que la Reforma fue el Renacimiento y la creación de nuevos comportamientos. Aprendieron a ejercer el autocontrol y pusieron en marcha un proceso de privatización de sus formas de vida ${ }^{46}$. Rechazaron el idioma del pueblo y la cultura popular en su conjunto.

La socialidad comunitaria estaba basada en tradiciones orales y visuales, con lo que no podía absorber con rapidez los cambios. Ciertamente, no

${ }_{43}$ Es sugerente el papel que J. Habermas confiere a cafés y salones en la creación de la opinión burguesa y del espacio público democrático, en Historia y critica de la opinión pública, Gustavo Gilli, Barcelona, 1983.

${ }^{44}$ Las páginas que R. Sennet dedica a describir este mundo son impecables. R. SENNET, Declive del bombre público, Península, Barcelona, 1985.

${ }^{45}$ A. Gouldner, La dialéctica de la ideología y la tecnología, Alianza, Madrid, 1978, pp. $125-156$.

${ }^{46} \mathrm{~N}$. Elias describe la construcción de las buenas formas sociales como un proceso de civilización. N. EliAs, El proceso de civilización, FCE, México, 1987, pp. 99 y ss. P. Aries describe también la formación del universo privado como el producto de un proceso donde la emergencia del Estado, la alfabetización y la religiosidad interior inducen nuevas realidades. Los caminos por los que estos acontecimientos penetran son de diverso tipo: literatura de las buenas formas, escritura (diario intimo, las cartas, confesiones, etc.), el gusto por la soledad, redescubrimiento del valor de la amistad, nuevas formas de concebir la vida diaria o de organizar la casa propia. P. Aries, Historia de la vida privada, op. cit., pp. 5-23. 
podía competir con la cultura de la burguesía y de la nobleza. Además, el crecimiento de las ciudades, la difusión de la enseñanza y el desarrollo de los modernos medios de transporte hizo inevitable el cambio.

Semejante ruptura indicaba que el mundo estaba cambiando y que ciertas formas de socialidad no tenían ya cabida en él.

El cambio se concreta en la conquista de la intimidad individual. Junto al individualismo en las costumbres, nos encontramos con que nacen unas nuevas formas de socialidad, especialmente en las ciudades y entre la ascendente clase burguesa. Son grupos que desarrollan una cultura de pequeñas sociedades consagradas a la conversación, la lectura en voz alta o el comentario. Si bien al principio se reunían en salones o en habitaciones privadas, a medida que fueron proliferando tomaron los cafés ${ }^{47}$ como espacio privilegiado de sus actividades. Muchos de estos grupos tuvieron tendencia a convertirse en instituciones reglamentadas, con lo cual perdieron espontaneidad y se transformaron en clubes, sociedades de pensamiento o incluso en academias científicas.

Quizá una de las instituciones que mejor refleja estas mutaciones es la familia. Cambia de sentido; ya no es sólo unidad económica o lugar de coacción para los individuos. Tiende a transformarse en lo que nunca antes había sido: un refugio, en donde uno escapa de las miradas del exterior. La práctica del matrimonio arreglado se dejó de lado en nombre del amor romántico y de un concepto de familia como refugio frente al mundo económico altamente competitivo. El sistema familiar burgués ${ }^{48}$ se apoyaba en un hogar centrado en los hijos y en la cuasiemancipación de la mujer y en el aislamiento estructural de la familia nuclear respecto al sistema de parentesco y de la sociedad en general. La familia encontró sustento ideológico y justificación en el concepto de vida doméstica como refugio en una sociedad que se presenta fría y competitiva. El concepto de familia como refugio daba por sentado la drástica separación entre trabajo y tiempo libre, y entre vida pública y vida privada. El surgimiento de la familia nuclear es indicador del alto valor que la sociedad moderna adjudicó a la privacidad.

Al desarrollar nuevas funciones, la familia, por una parte, absorbe al individuo, al que acoge y defiende; por otra, se separa claramente del espacio público. Su expansión se produce a expensas de la socialidad anónima de la calle y de la plaza.

Pero la familia nuclear es consecuencia de un proceso general: el de la privatización de formas y usos sociales. La construcción de la esfera priva-

47 Véase el ya citado texto de J. Habermas, Historia y crítica de la opinión pública, Gustavo Gilli, Barcelona. También, el ya citado trabajo de P. Aries y G. Duby (comps.), Historia de la vida privada, tomo 3.

${ }^{48} \mathrm{CH}$. LAsCH, Refugio en un mundo despiadado, Gedisa, Barcelona, 1987. Véase también la obra de J. Godoy (comp.), Historia de la familia, tomo II, Alianza, Madrid, 1989. 
da implica la crisis de las formas de socialidad comunitaria y la emergencia del individuo como productor de «su» sociedad ${ }^{49}$.

El problema que la nueva sociedad -moderna y parcialmente industrializada - debe abordar es encontrar un nuevo principio de articulación comunitaria que parta del individuo y de las manifestaciones de la privacidad, pero que no puede usar, exclusivamente, la tradición como dosel sagrado ${ }^{50}$ de su reproducción.

Las formas de socialidad comunitarias tradicionales manifiestan la progresiva pérdida de importancia de lazos primarios (familia, gremios y aldea). Por otra parte, surge con fuerza una nueva corriente: el nacionalismo, que intenta sustituir las viejas mediaciones entre el individuo y los grandes fines de la civilización por una nueva forma de comunidad no política, pero políticamente generada desde el Estado: la Nación. El sentimiento de pertenencia y la adscripción al Nosotros comunitario, en la situación moderna, requiere la identificación de cada individuo con una comunidad necesariamente abstracta. El problema lo plantea Durkheim con absoluta nitidez: ¿cuáles son los lazos que unen a los hombres?

La Nación abre la posibilidad de pensar la sociedad como un todo y darla un carácter histórico y espacial. Lo que ocurre es que la Nación es la concreta representación de la sociedad comunitaria. Sociedad que se corresponde con el territorio definido estatal por el Estado. El problema moderno, tal y como se plantea, es la búsqueda de valores compartidos por todos aquellos que se sienten miembros del grupo y que articulan sistemas de creencias compartidas.

La conciencia moderna comunitaria no puede ya depender de la arbitrariedad tradicional. El principio moderno de articulación simbólico grupal es la realidad nacional. El discurso nacional cierra el orden de seguridad moderno y anuncia la creencia en la sociedad comunitaria, protegida por el Estado.

La fraccionada sociedad moderna encuentra en el discurso nacional la posibilidad de pensar la sociedad como un todo. La Nación opera socialmente como vínculo de identidad y mecanismo central de integración. Si los lazos comunitarios tradicionales están en trance de sustitución por lazos Gessellschaft, la Nación opera como sustituto ideal, motivo de adscripción e identificación.

La Nación, en términos modernos, opera como creadora de comunidad e identidad colectiva. Aparece como la imagen dominante que corresponde a la comunidad política territorial que es el Estado Moderno. Ocurre que en la sociedad moderna la comunidad prototípica - sociedad nacionalestá protegida por el Estado. Los connacionales tienen en común la perte-

49 Véase Steven Lukes, El individualismo, Península, Barcelona, 1982.

50 Tomo este concepto de la obra de P. Berger, Para una teoría sociológica de la religión, Kairós, Barcelona, 1978. 
nencia a la comunidad nacional. El vínculo nacional se transforma en vínculo de fraternidad ${ }^{51}$.

La idea moderna de comunidad no busca su origen en la tradición o en la religión, sino que se corresponde con la idea de sociedad nacional, formada por individuos, transformados en ciudadanos, adscritos e identificados a la conciencia del Nosotros, lo que les hace adscribirse a una nueva lógica fraternal: la lógica estatal que persigue una pretensión originaria ${ }^{52}$; la nacionalización del Estado, es decir, intenta provocar el olvido de particularismos y sentimientos primordiales ${ }^{53}$ que existen en las diferentes partes del territorio definido por el Estado, territorio estatal. La pauta cultural de vida grupal ${ }^{54}$ tradicional y particular, debe reconvertirse para que los individuos se adscriban a la «lógica fraternal» nacional. Si la política civil ${ }^{55}$ tiene éxito, triunfa el proceso de disolución de los vínculos tradicionales y su acervo de conocimiento ${ }^{56}$.

En todos los casos, la idea de Nación segrega nuevos principios de articulación comunitaria. De hecho, la construcción de la comunidad moderna se transforma en la producción de una cultura nacional ${ }^{57}$ y de todo un intrincado entramado de señales y signos de identificación. La creación de una lengua nacional, un nuevo alfabeto, la reivindicación de una historia que se pretende historia de la nación, nuevos marcos económicos, etc., persiguen la justificación de una nueva idea de comunidad y nuevas formas de socialidad.

La pertenencia a la comunidad nacional es la respuesta moderna al proceso de constitución de la sociedad occidental, urbana e industrial y, al

51 Casi todos los estudios sobre la formación del nacionalismo insisten en el carácter comunitario de la idea de Nación. Podemos verlo en J. BRAND, The National Movement in Scotland, Londres, 1978; R. Dulong, La Question bretonne, Collins, París, 1975; E. Gellener, Naciones y nacionalismo, Alianza, Madrid, 1987; P. GREMION, Le Pouvoir Pèripherique, Evil, París, 1976; M. Hechter, Interal Colonialism, Londres, 1975; H. KoHnN, Historia del nacionalismo, FCE, México, 1949; L. QUÈRÈ, Jeux Interdits à la frontière, Anthropos, París, 1978; R. NisBET, The Quest for Community, Oxford University Press, 1953; R. Rogowski (comp.), New Nationalisms of the National States in Western Europe, Princeton University Press, 1975.

52 Véase R. Nisbet, The Quest for Community, op. cit. Es sugerente la idea de P. Birnbaum, Logique de l'Etat, Fayard, París, 1982, y P. Binhaum y P. Bodie, Sociologie de l'Etat, Grasset, París, 1979. 262.

${ }^{53}$ Véase C. Geertz, Interpretación de las culturas, Gedisa, Barcelona, 1987, pp. 219.

${ }^{54}$ La expresión, tomada de A. Schutz, Estudios de teoría social. El forastero, Amorrortu, B. Aires, 1974 , p. 96. La define de la siguiente manera: «designaremos (...) todas las valoraciones, instituciones y sistemas de orientación y guías peculiares (tales como usos y costumbres, leyes, hábitos, etiquetas y modas) que caracterizan a todo grupo social en un momento determinado de su historia».

${ }^{55}$ Véase G. GeErTz, La interpretación de las culturas, Gedisa, Barcelona, 1987, pp. 219 262.

56 Véase A. Schutz, Las estructuras del mundo de la vida, Amorrortu, B. Aires, 1977, pp. 109-182.

57 El mejor análisis es el realizado por E. GelLnER en Naciones y nacionalismos, Alianza, Madrid, 1989. 
mismo tiempo, es una respuesta a la búsqueda de dimensiones sociales significantes para los actores sociales.

La búsqueda de formas de articulación social para la complejidad moderna es, de hecho, uno de los objetivos perseguidos por los sociólogos clásicos. Su mirada al pasado es búsqueda de respuestas para la realidad presente, porque todos perciben que la tradición y el principio comunitario que la articulaba no es válido para la compleja y ambigua sociedad moderna. Tönnies ${ }^{58}$ describía el camino de iniciación moderno y lo resumía en su celebérrima fórmula - de la comunidad a la sociedad-. Años antes el padre de los «estudios democráticos», A. de Tocqueville ${ }^{59}$, ya había advertido sobre el profundo significado del cambio; mundo aristocrático frente a mundo democrático. Ni M. Weber, ni Durkheim, ni Marx, ni Simmel huyen de semejante problemática.

Tönnies advertía que la comunidad es expresión de la voluntad natural y la vida, así organizada, se funda en la unidad y en la totalidad. Por el contrario, la sociedad hace referencia a una forma artificial de agrupación humana. En el ámbito de la modernidad, las relaciones son compromisos que se contraen para conseguir un objetivo concreto. El individuo está mediado por el fin u objetivo a alcanzar, de tal forma que la imagen que Tönnies construye del ser humano lo presenta como un ser interesado, calculador, que se rige por una racionalidad que más tarde $\mathrm{M}$. Weber llamará con arreglo a fines. No es extraño que frente al «cálido» hogar tradicional, la racionalidad moderna no sea más que un lugar amenazador e inhóspito, porque el cálculo, la eficacia y la obtención de resultados no parecen las guías más adecuadas para reconstruir «hogares» estables en la sociedad moderna. Pero, paradójicamente, sólo en condiciones modernas puede el individuo ejercer su libertad y ser llamado por su nombre. La pérdida de comunidad tradicional, a pesar de ser vista con nostalgia, es condición de libertad y sólo la modernidad, a pesar de sus paradojas, asegura que el hombre pueda ejercerla. Otra cosa es que perdidas las referencias comunales, la sociedad moderna necesite vínculos de unión, vínculos, como afirmará Durkheim, solidarios.

Durkheim ${ }^{60}$ analiza el tránsito en términos del paso de la solidaridad mecánica a la orgánica. La sociedad de la solidaridad orgánica, basada en la diferenciación y en la especialización funcional, hace de los individuos seres interdependientes, porque el pluralismo moderno subordina cada individuo al conjunto de la sociedad.

Si la sociedad moderna somete a sus miembros a la práctica de la autonomía, la autosuficiencia humana topaba con los límites impuestos por

58 Véase TÖnNies, Comunidad y asociación, op. cit.

59 Véanse A. DE Tocquevilie, El Antiguo Régimen y la Revolución, Guadarrama, Madrid, 1978; Recuerdos de la Revolución de 1848, Editora Nacional, Madrid, 1980; Igualdad social y libertad política, Magisterio Español, 1978.

${ }^{60}$ E. Durkheim, De la división del trabajo social, Shapire, B. Aires, 1960; El suicidio, Akal, Madrid; El socialismo, Editora Nacional, Madrid. 
el proceso general de racionalización. El individuo solidario de Durkheim creía poder huir de la anomía, haciéndose dependiente. La jaula weberiana vive, en cambio, sus condiciones de encadenamiento. La calculabilidad, el reglamento y la permisibilidad encierran al hombre en el ritmo laboral y lo encadenan a su propia obra. Pero el individuo moderno no puede serlo, salvo desde la asunción de la paradoja moderna. Como indica A. Dawe ${ }^{61}$, la sociología clásica está atravesada por el triunfo del sistema; los individuos están arrancados de sus raíces por la acción humana que los creó. El problema quizá no sea tanto el triunfo del sistema como el sistemático olvido analítico de la realidad microsocial, porque, afirma A. Pérez-Agote, la sociología «se desarrolla en el terreno de las construcciones teóricas concretas, más como ciencia de la sociedad que como ciencia de lo social (...). Este predominio de la sociedad sobre el individuo, de lo macrosocial sobre lo microsocial lleva consigo, en cierta manera, el predominio de las concepciones evolucionistas (evolución de los tipos de sociedades) y objetivistas sobre los análisis de mecanismos sociales concretos más cercanos a los individuos» ${ }^{62}$. Ocurre también que, como dice Ch. Tilly ${ }^{63}$ : «El siglo XIX pesa sobre nosotros como una pesadilla.»

El peso del sistema no elimina la acción comunitaria, ni tampoco sus formas de socialidad; otra cosa es que la comunidad, al igual que ocurriera con la religión, no ocupe el lugar central en la red de vínculos sociales, ni pueda aspirar a regenerar las nociones de totalidad y homogeneidad. Con los clásicos ocurre que si ponen el énfasis en aspectos macro o en la evolución de las sociedades, no olvidan la profunda significación de las relaciones comunitarias. La Gessellschaft de Tönnies anuncia más el triunfo de la razón moderna que la desaparición de la Gemeinschaft; en Durkheim la creación de la realidad moral integradora, es consustancial a la solidaridad orgánica; en $M$. Weber la acción racional con arreglo a fines no elimina ni la acción con arreglo a valores, ni la acción afectiva, ni tampoco la tradicional.

En el fondo, jamás ha existido un individuo autónomo, ni habría podido existir. La transición de la tradición a la modernidad, no fue nunca la de la comunidad al individuo. Detrás de esta fórmula había dos procesos que marcaron las pautas convencionales de la interpretación sociológica: por una parte, la ruptura de la tradición y, por otra, la «embriaguez» generada por la estructuración moderna del sistema de creencias que convertía al individuo en centro de una sociedad que aparecía como algo a explicar, en ocasiones, inaccesible y, en otras, incomprensible. Detrás de esta fórmula lo que existió fue un cambio en los detalles de la vida. La Gessellscbaft se desarrollaba e imponía su nuevo estilo, pero la Gemeinschaft creaba, a su

6. A. Dawe, Teorias de la acción social; R. NISBET y T. BOTTOMORE, op. cit., p. 465.

62 A. Pérez-Agote, La sociedad y lo social, UPV/EHU, Leioa, 1989, p. 15.

${ }^{63} \mathrm{Ch}$. TILly, Grandes estructuras. Procesos amplios. Comparaciones enormes, Alianza, Madrid, 1991, p. 15. 
vez, nuevas formas de socialidad. Lo que la modernidad anunció fue, sobre todo, la paradoja y la ambigüedad de la vida en sociedad. Así anunció la soledad, el enclaustramiento, la privatización. Pero, sin embargo, el individuo siguió construyendo su vida y su realidad. La experiencia es intensa e intrínsecamente ambigua. Por un lado, el individualismo y la reificación constituyen, como tal, una experiencia básica de la sociedad moderna; por otro, los individuos convencidos de su realidad, generando formas comunitarias. Este principio de ambigüedad es recogido por N. Elias, cuando dice: «Esta configuración social de las relaciones humanas no ha extinguido la necesidad elemental que todo individuo tiene de calor y espontaneidad en su relación con otros. No ha hecho desaparecer el deseo de seguridad y estabilidad de la afirmación emocional de la propia persona a través de los demás, ni su contrapartida, la necesidad de convivir con otras personas con las que se está a gusto» ${ }^{64}$.

\section{LA AMBIGÜEDAD DE LOS REFUGIOS MODERNOS}

La ambigüedad es la única base posible de acción. La experiencia es, a la vez, individualista y comunitaria, es decir, se vive dentro de realidades múltiples que, en muchos casos, no admiten la presumible coherencia. Por el contrario, se puede vivir dentro del mundo privado y fuera de él en conexión con los otros, lo que ocurre es que la comunidad no tiene la misma estructura de plausibilidad que en la tradición, ni tampoco las mismas formas de expresión para su socialidad. A. Schutz ${ }^{65}$ delimita, con admirable precisión, que el conocimiento del hombre que actúa y piensa no es homogéneo: «es incoherente (...) sólo parcialmente claro y (...) en modo alguno exento de contradicciones. Es incoherente porque los intereses del individuo que determinan la significatividad de los objetos elegidos para su ulterior indagación no están integrados, a su vez, en un sistema coherente (...). En la vida cotidiana, al hombre no le interesa más que parcialmente (...) la claridad de su conocimiento, o sea, la plena percepción de las relaciones entre los elementos de su mundo y los principios generales que gobiernan esas relaciones (...). Puede considerar igualmente válidos enunciados que, de hecho, son incompatibles entre sí».

Este tipo de conocimiento adquiere así, para los miembros del grupo, la apariencia de coherencia y claridad para convencer a cualquiera que puede comprender y ser comprendido. Mientras en la sociedad tradicional han vivido en mundos más o menos integrados y, como dice P. Berger: «en la familia, en el trabajo, en la actividad política o en la participación en fiestas y ceremonias el individuo estaba siempre en el mismo mundo» ${ }^{66}$. La vida en

${ }^{64}$ N. Elias, La sociedad de los individuos, Península, Barcelona, 1990.

65 A. Schutz, Estudios de teoría social. El forastero, op. cit., pp. 97-98.

${ }^{66}$ P. Berger, B. Berger y H. Kellner, Un mundo sin hogar, op. cit., p. 64. 
la sociedad moderna es diferente, suele estar segmentada en un grado muy elevado y múltiples mundos sociales se presentan ante los individuos.

La pluralización encuentra su espacio más significativo en la vida urbana. La comunidad y las formas de socialidad comunitaria se ven reducidas a zonas concretas en la gran urbe y a espacios alrededor de la centralidad familiar. Nada mejor que muchas de las investigaciones de la escuela de Chicago para comprender la nueva relación entre hombre y ambiente desde el punto de vista de las relaciones entre los individuos humanos, y las instituciones y formas de estructuración por el otro, orientadas a menudo según modelos de origen botánico y zoológico ${ }^{67}$. Los intereses predominantes en las investigaciones de la escuela de Chicago resultan de los títulos de algunas de las monografías que aparecieron: El vagabundo, de N. Anderson; La banda, de I. M. Trasher; Desorganización de la familia y conflictos familiares, de E. Russell Mowrer; El ghetto, de L. Wirth; La buelga, de E. T. Hiller; Cosas de ciudades pequeñas, de A. Blumenthal, etc. ${ }^{68}$. L. Wirth ${ }^{69}$ será quien de forma más lúcida y provocativa plantee la mencionada problemática siguiendo la comprensión del medio urbano. Definirá la ciudad por tres características: densidad, heterogeneidad y número. Las consecuencias de su definición demuestran la precariedad de cualquier solución comunitaria. De la heterogeneidad nace la segregación espacial en la ciudad y, por tanto, la división del ambiente urbano en áreas naturales. También que la solidaridad típica de la comunidad rural es sustituida, en la ciudad, por mecanismos de competición y de control social formalizado. En cuanto al número, muchos habitantes generan que el ciudadano esté condenado a encontrarse con casi todos, pero a permanecer siempre solo porque la relación con los demás se racionaliza y es cada vez menos emotiva. El contacto social en el medio urbano es superficial, anónimo y rápido. Además, el número de habitantes no sólo impide un conocimiento directo y profundo, sino que obliga también a la comunicación a servirse de medios indirectos. La densidad agrava, aún más, estas tendencias.

La heterogeneidad genera que cada individuo deba afiliarse a una pluralidad de grupos que satisfacen diversas funciones, en conformidad con la diversidad de las exigencias y los intereses de cada uno. Ocurre así que esta pertenencia pluralista excluye la devoción total del individuo al grupo.

La construcción de refugios se adivina como la salida más eficaz a la enorme pluralidad moderna. La conciencia grupal y comunitaria puede realizarse en la esfera privada. Claro está que esto supone aceptar que un aspecto fundamental de esta pluralización es la dicotomía entre el mundo

${ }^{67}$ Hay una magnífica recopilación de G. A. THEodorson, Estudios de ecología bumana ( 2 tomos), Labor, Barcelona, 1974. Es muy instructivo el capítulo «Estudios de Comunidad», en T. Adorno y M. Horkheimer, La sociedad, Proteo, B. Aires, 1969, pp. 149-170.

68 Véase T. Adorno y M. Horkheimer, op. cit., p. 152.

69 L. WIRTH, El urbanismo como modo de vida, Ediciones Tres, B. Aires, 1971. 
público y el mundo privado, o mejor, aceptar la especialización del mundo privado como lugar del «verdadero encuentro». Pero, probablemente, estamos ya en otra dimensión. Cuesta no aceptar la idea expuesta por R. Bellah de que «mientras que una comunidad trata de constituirse en un todo, celebrando la interdependencia de la vida pública y privada y de las distintas vocaciones de todos ${ }^{70}$, la aceptación del pluralismo y la segmentación social provoca la desaparición de la comunidad, tal y como tradicionalmente ha sido definida, o en todo caso, la comunidad no será más que un momento del acontecer humano. El mismo Bellah nos habla con nitidez de esta transformación diferenciando la comunidad del enclave de vida: «El estilo de vida es básicamente segmentario y celebra el narcisismo de la similitud. Normalmente implica, de forma explícita, una oposición a otros que no comparten el estilo de vida de uno. Por eso, no hablamos de comunidades de estilo de vida (...) sino de enclaves de estilo de vida. Tales enclaves son segmentarios en dos sentidos. Sólo incluyen un segmento de cada individuo, ya que afectan únicamente a la vida privada, sobre todo, al ocio y al consumo, y son socialmente segmentarias, ya que sólo implican a los individuos con un mismo estilo de vida. Los diferentes no son necesariamente despreciados. Puede ser que se les tolere de buena gana. Pero son irrelevantes o incluso invisibles en términos del propio enclave de estilo de vida» ${ }^{71}$. En parte, el enclave de estilo de vida, sin la adscripción afectiva que suele tener la relación comunitaria, cumple algunas de sus funciones fundamentales: «Podríamos considerar el enclave de estilo de vida como una forma apropiada de apoyo colectivo en una sociedad, por lo demás, radicalmente individualizada (...) puesto que el objetivo de la individuación siempre ha estado ligado a la habilidad de encontrar otras personas que reflejen y reafirmen la individualidad de uno, el enclave de estilo de vida podría ser, quizá, la necesaria forma social de la vida privada en una sociedad como la nuestra. (...) Pero además en una época en que el trabajo raras veces es una vocación y en la que pocas descubren el sentido de quienes son en la participación pública como ciudadanos el enclave de estilo de vida, a pesar de ser, a menudo, frágil y poco profundo, desempeña esta función para todos nosotros» ${ }^{72}$.

La dicotomización público-privado define dos grandes espacios de actuación personal, uno es è dèl trábajo como manifestación àè universu público, otro es el enclave de vida expresión de la vida privada. Pero si la esfera privada ha servido «como una especie de mecanismo de contrapeso que proporciona significaciones y actividades dotadas de sentido» ${ }^{73}$, también parece evidente que tiene aspectos problemáticos.

70 R. Bellah, R. Madsen, W. M. Sullivan, S. Swidler y S. M. Tipton, Hábitos del corazón, op. cit., p. 104.

71 R. BELLAH, op. cit., p. 104.

72 R. Bellah, op. cit., pp. 105-107.

73 P. Berger, B. Berger y H. Kellner, op. cit., p. 177 
La «era del vacío» ${ }^{74}$ genera poca fiabilidad en las instituciones que deben dar cuerpo a este espacio y además el individualismo narcisista ${ }^{75}$, en su búsqueda del sí mismo y «apartado de la familia, la religión y la vocación como fuentes de autoridad, deber y ejemplo moral, el yo trata de elaborar su propia forma de acción persiguiendo autónomamente la felicidad y cumpliendo sus deseos» ${ }^{76}$. La lógica terapéutica ${ }^{77}$ ayuda a «transformar nuestra experiencia de esta sociedad en algo con significación personal, y más tarde en acción social. En su intento de reunificar el yo, la actitud terapéutica nos aleja de roles sociales, relaciones y prácticas específicas, y de sus medidas concomitantes de autoridad, deber y virtud» ${ }^{78}$. Los refugios centrados alrededor de la familia, amigos y asociaciones secundarias, tradicionales espacios comunitarios, se ven sometidos, a su vez, al proceso de especialización e individualización generales. La búsqueda de comunidad se transforma en un anhelo, porque, como expresa el mencionado Lipovestsky ${ }^{79}$, el proceso de personalización ha creado una cultura destrascendentalizada, es decir, es posible vivir sin ideales, sin metas, más allá de una cotidianeidad desprovista de grandeza. La apatía gobierna el mundo público mientras la indiferencia preside los vínculos privados. El encuentro con el prójimo se da desde una concentración exclusiva en lo personal. El hedonismo merece otras consideraciones ${ }^{80}$, es su relación con la conquista de la intimidad ${ }^{81}$ y el narcicismo ${ }^{82}$ lo que lleva a R. Sennett a tratar el fenómeno de la comunidad destructiva ${ }^{83}$.

Para R. Sennett, comunidad es un término engañoso: «una comunidad es una particular variedad de grupo social en la que los hombres creen que ellos comparten algo juntos. El sentimiento de comunidad es fraternal (...). El vínculo de comunidad es el de percibir identidad común, un placer en reconocernos a nosotros y lo que somos» ${ }^{84}$.

Las relaciones comunitarias, bajo las condiciones de la sociedad industrial avanzada, son destructivas porque una comunidad no es simplemente

74 G. Lipovestsky, La era del vacio, Anagrama, Barcelona, 1978.

${ }^{75}$ Ch. LASCH, The Culture of Narcisism, Warner Books, N. York, 1979.

76 R. BELLAH, op. cit., p. 111.

77 R. RiefF, The Triumph of the Therapeutic, Penguin, Middlesex, 1966.

78 R. Bellah, op. cit., p. 171.

79 G. LIPOVESTSKY, op. cit.

80 Véase D. BELL, Las contradicciones culturales del capitalismo, Alianza, Madrid, 1982. Explica el papel del hedonismo como sustituto de la ética protestante, y la búsqueda del placer y el consumo, como justificación del capitalismo de expansión.

81 El magnífico estudio de Helena BÉJAR, El ámbito intimo. Privacidad, individualismo $y$ modernidad, Alianza, Madrid, 1988, pp. 165-231, es una lúcida «exposición de motivos» de la sociedad intima.

${ }^{82}$ El narcisismo es objeto de análisis en Ch. Lasch, op. cit. También, R. Sennetr, Narcisismo y cultura moderna, Kairós, Barcelona. Se pueden leer las páginas que R. SENNETT dedica a esta problemática en El declive del hombre público, op. cit., pp. 387-421.

83 Véanse R. SenNetT, El declive del bombre público, op. cit., pp. 363-381; R. SenNeTt, Vida urbana e identidad personal, Península, Barcelona, 1974.

84 R. SENNETT, Vida urbana e identidad personal, op. cit., p. 52. 
un grupo social o un agregado estadístico de individuos, sino que «es un grupo en el que las personas se pertenecen mutuamente, comparten algo en común» ${ }^{85}$. El sentimiento Nosotros que articula la comunidad «es un modo que tienen los hombres de evitar la necesidad de analizarse mutuamente más a fondo; en vez de esto, los hombres se imaginan que lo conocen todo unos de otros, y su conocimiento se convierte en una convicción de que deben ser lo mismo» ${ }^{86}$. Pertenecerse mutuamente se convierte en una sensación compartida de lo que pensamos que deberíamos ser como seres sociales. La solidaridad comunitaria no es así más que un mito, sostenido más por la conformidad que por la convicción.

La vida en comunidad tiene tres consecuencias destacables. La primera es la pérdida de participación real en la vida comunitaria porque «sentir vínculos comunes sin experiencia común sucede porque los hombres temen participar, temen los peligros y los desafíos de ella, temen su dolor ${ }^{87}$. Una segunda consecuencia es la represión de los discrepantes. Quienes desafían las normas «tenían que enmudecer con el fin de que la similitud, la semejanza, pudiera mantenerse (...). Permitir la libertad de desviarse sería preocuparse por lo desconocido, el otro, en los contactos sociales» ${ }^{88}$. La tercera consecuencia no es menos preocupante. Sennett dirá que «los individuos en la comunidad han logrado una sensación coherente de ellos mismos precisamente gracias a eludir experiencias penosas, confrontaciones desordenadas y experimentos en la formación de su propia identidad. Al existir tan poca tolerancia para el desorden, la erupción de la tensión social se transforma en una situación en la que los métodos fundamentales de agresión, fuerza violenta y represión parecen ofrecer, ya no solamente justificación, sino seguridad de vivir» ${ }^{89}$.

La defensa de la comunidad se erigirá sobre el mito de la solidaridad grupal, cuando ésta es más producto del miedo, de la inseguridad y del temor a lo desconocido, que de las relaciones sociales. La sociedad contemporánea elimina las condiciones de normalización comunitaria, porque no crea relaciones sociales, sino refugios donde «mezclarse» con los iguales, huyendo del dolor exterior y de las relaciones conflictivas. El sentido moderno de comunidad encuentra refugio en escenarios íntimos, porque no puede desarrollarse fuera de ellos; es más, la situación comunitaria excluye el encuentro con quienes no forman parte del Nosotros.

85 R. SENNETT, Vida urbana e identidad personal, op. cit., p. 59.

${ }^{86}$ R. SENNETT, Vida urbana e identidad personal, op. cit., p. 66.

87 R. SENNETT, Vida urbana e identidad personal, op. cit., p. 63.

88 R. Sennet, Vida urbana e identidad personal, op. cit., p. 63.

${ }^{89}$ R. SENnetT, Vida urbana e identidad personal, op. cit., pp. 64-65. 


\section{MEMORIA, TRADICION Y COMUNIDAD}

El tiempo moderno es paradójico y la falta de hogar es una constante amenaza. La necesidad del encuentro social no significa que éste deba seguir derroteros comunitarios. En todo caso, la comunidad debe desprenderse de su propio mito. Mito, procedente del pensamiento conservador decimonónico, quien en su intento de afirmar la tradición y negar la razón contractual moderna construyó una idea de comunidad y la elevó a la categoría de mito. La comunidad «conservadora» proyectaba una edad de oro, donde los individuos vivían en armonía, sin conflictos, agrupados por la conciencia del Nosotros, cohesionado por la solidaridad grupal. La vida en comunidad no sólo era defendible, sino que la sociedad debía organizarse desde estos principios. Pero la comunidad proyectada poco tenía que ver con la realidad. Allí donde se hablaba de armonía y cohesión, destacaba el miedo, la desorganización y el conflicto soterrado. La tradición no era el espacio de bondades previsto, sino la realidad de una sociedad atrapada en su inmovilidad, finitud y falta de perspectivas.

La perspectiva moderna transforma la comunidad en un término polisémico que indica cosas muy distintas; desde una comunidad étnica, hasta una comunidad de intereses, pero en todos los casos resaltan el carácter problemático de semejante construcción social. No sólo porque el espíritu moderno imponga una cultura de la separación, sino porque la modernidad genera múltiples tipos de encuentros sociales, en tanto la realidad se fragmenta en múltiples micromundos y la complejidad invade los contactos personales. No obstante, la ambigüedad del comportamiento genera micromundos comunitarios, no tanto por obligación, sino por necesidad. La cultura de la separación integra, como afirma R. Bellah ${ }^{90}$, de dos formas: «Uno es el sueño del éxito personal (...). El segundo es la descripción de vivos sentimientos personales (...) y los mismos bienes de consumo que la televisión pone ante nosotros con tanta insistencia nos integran proporcionándonos símbolos de nuestra versión de la buena vida.» Una cultura de este tipo es problemática, padece de déficit en la integración.

La cultura debe estar asociada a tradiciones. Allí donde persisten tradiciones se puede refundar una comunidad, porque la tradición sustenta el universo simbólico ${ }^{91}$ del grupo. Sólo el grupo con historia posee valores comunitarios porque éstos, en el fondo, están para proteger la tradición. Sin tradiciones conservadas, inventadas o recreadas, la comunidad se transforma en un micromundo. La idea comunitaria del Nosotros es el crisol de los valores de la costumbre, porque el sentimiento de pertenencia hace referencia a un sistema de creencias, asegurado mediante una comunidad de memoria. Pero la tradición es un bien escaso en nuestras complejas

90 R. Bellah, op cit., p. 356.

91 El término está tomado de la obra de P. BERGER y T. LIUCKMAN, La construcción social de la realidad, Amorrortu, B. Aires, 1973. 
sociedades, por eso la comunidad es casi monopolio de colectivos con raíces, de grupos con memoria histórica. No podemos decir que la comunidad haya desaparecido, pero sí podríamos afirmar que comunidad sin tradición no deja de ser un concepto, vacío de contenido, porque el contenido es la estructura de comunicación que permite fundar una lógica de la diferencia y gestar un centro simbólico, más allá de los valores privados del momento. Otra cosa es que el encuentro social siga siendo una necesidad de la socialidad, aunque sea articulado desde la esfera privada y encuentren en el ocio y el consumo el enclave de vida deseado. Ni la escisión público-privado, ni la esfera privada como enclave de vida, ni, por supuesto, la sociedad íntima o el narcisismo colectivo parecen motivos suficientes para gestar una refundación de valores comunitarios. Sólo el mantenimiento de un tipo u otro de tradición es motivo de comunidad. No debiera extrañarnos que aquellos grupos (étnicos, sobre todo, pero también políticos, religiosos y de género) que siguen asegurando su marco de referencia desde la memoria histórica sean los «poseedores» del discurso comunitario. Lo demás parece más bien intentar dar sentido a una estrategia de supervivencia cultural, en términos tribales ${ }^{92}$. La comunidad, en estos casos, es un anhelo, una búsqueda incesante de sentido; descubrimientos y redescubrimientos de realidades referenciales, agotadas en su mismo uso conceptual.

92 Véase la sugerente obra de M. MAFFESOLI, El tiempo de las tribus, Icaria, Barcelona, 1990. 